\title{
A new ENSO index derived from satellite measurements of column ozone
}

\author{
J. R. Ziemke ${ }^{1,2}$, S. Chandra ${ }^{1,2}$, L. D. Oman ${ }^{2}$, and P. K. Bhartia ${ }^{2}$ \\ ${ }^{1}$ Goddard Earth Sciences and Technology Center, University of Maryland Baltimore County, Baltimore, Maryland, USA \\ ${ }^{2}$ NASA Goddard Space Flight Center, Greenbelt, Maryland, USA
}

Received: 15 December 2009 - Published in Atmos. Chem. Phys. Discuss.: 4 February 2010

Revised: 8 April 2010 - Accepted: 12 April 2010 - Published: 21 April 2010

\begin{abstract}
Column Ozone measured in tropical latitudes from Nimbus 7 total ozone mapping spectrometer (TOMS), Earth Probe TOMS, solar backscatter ultraviolet (SBUV), and Aura ozone monitoring instrument (OMI) are used to derive an El Nino-Southern Oscillation (ENSO) index. This index, which covers a time period from 1979 to the present, is defined as the "Ozone ENSO Index" (OEI) and is the first developed from atmospheric trace gas measurements. The OEI is constructed by first averaging monthly mean column ozone over two broad regions in the western and eastern Pacific and then taking their difference. This differencing yields a self-calibrating ENSO index which is independent of individual instrument calibration offsets and drifts in measurements over the long record. The combined Aura OMI and MLS ozone data confirm that zonal variability in total column ozone in the tropics caused by ENSO events lies almost entirely in the troposphere. As a result, the OEI can be derived directly from total column ozone instead of tropospheric column ozone. For clear-sky ozone measurements $\mathrm{a}+1 \mathrm{~K}$ change in Nino 3.4 index corresponds to +2.9 Dobson Unit (DU) change in the OEI, while a $+1 \mathrm{hPa}$ change in SOI coincides with a $-1.7 \mathrm{DU}$ change in the OEI. For ozone measurements under all cloud conditions these numbers are +2.4 DU and -1.4 DU, respectively. As an ENSO index based upon ozone, it is potentially useful in evaluating climate models predicting long term changes in ozone and other trace gases.
\end{abstract}

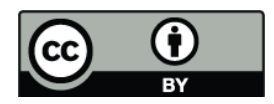

Correspondence to: J. R. Ziemke (j. r. ziemke@nasa.gov)

\section{Introduction}

It is well known that El Nino Southern Oscillation (ENSO) events in the tropical Pacific are associated with an atmosphere-ocean coupled interaction which induces interannual ( $\sim 2-7$ year periods) planetary-scale changes in ocean sea-surface temperature and currents, surface pressure, atmospheric temperature and winds, clouds and precipitation, and trace gases in the troposphere. The term "ENSO" is commonly referred to either El Nino (anomalously warm ocean temperatures in the tropical eastern Pacific - i.e., "warm phase") or La Nina (anomalously cool ocean temperatures in the tropical eastern Pacific - i.e., "cool phase"). ENSO events represent changes in tropical sea-surface temperature and other geophysical parameters relative to average conditions which are driven by the persistent Walker Circulation. The Walker Circulation is characterized by warm ocean temperatures and moist convection in the western Pacific and cooler ocean temperatures and smaller convective activity in the eastern Pacific.

Trenberth (1997) has provided an historical account of ENSO and the various geophysical indices used to represent these events. El Nino events have long been identified by anomalously warm ocean currents running southward along the coasts of Peru and Ecuador which alter the meteorological and ecological conditions in these regions. As Trenberth (1997) implies, it is difficult to define ENSO and there is really not one single universal ENSO index fully representing all the related complex physical oceanic and atmospheric conditions. Historically, there have been many indices defined to represent ENSO events. Two well known ENSO indices are based upon sea surface pressure differences at Tahiti and Darwin (dating from the 1880's) and the Nino 3.4 index based upon sea-surface temperature anomalies starting

Published by Copernicus Publications on behalf of the European Geosciences Union. 
in 1950. These two ENSO indices are available from the NOAA sea-surface temperature indices website (http://www. cpc.ncep.noaa.gov/data/indices/). Other ENSO indices used in published literature have included satellite-derived precipitation (e.g., Curtis and Adler, 2000), a Multivariate ENSO Index (http://www.cdc.noaa.gov/people/klaus.wolter/MEI/), and many variations including winds, temperatures, and Outgoing Longwave Radiation in the troposphere. Some of these latter indices can be obtained via the internet which includes the above NOAA sea-surface temperature indices website.

El Nino events have been shown by many observational and modeling studies to have an important effect on the abundances of tropospheric aerosols and trace gases in the tropical Pacific including ozone, $\mathrm{H}_{2} \mathrm{O}, \mathrm{CO}$, and $\mathrm{NO}_{\mathrm{x}}\left(\mathrm{NO}+\mathrm{NO}_{2}\right)$ (e.g., Langford et al., 1997; Chandra et al., 1998, 2002; Ziemke et al., 1998; Fujiwara et al., 1999; Sudo and Takahashi, 2001; Peters et al., 2001; Thompson et al., 2001; Newchurch et al., 2001; Zeng and Pyle, 2005; Logan et al., 2008; Chandra et al., 2009; Ziemke et al., 2009). The El Nino events coincide with dry conditions and large-scale biomass burning in Indonesia which generate large regional increases in atmospheric particulates and trace gases including ozone. The largest measured El Nino-related changes (increases) in tropospheric column ozone (TCO) in the tropics occurred during September-November 1997 over Indonesia in the western Pacific with up to 25 Dobson Units (DU) elevations over average levels (e.g., Chandra et al., 1998; Fujiwara, et al., 1999). These increases in TCO were examined in detail by Sudo and Takahashi (2001) and Chandra et al. (2002) using observational data in combination with 3D photochemical transport models. About half of the increases in TCO over Indonesia during September-November 1997 were attributed to biomass burning with remaining amounts attributed to large-scale ocean-atmosphere dynamical changes caused by El Nino.

While biomass burning may substantially increase TCO in Indonesia, it is not the major source of anomalous ozone changes in the tropics related to El Nino. During El Nino the shift in sea-surface temperature and associated deep convection from the western to the eastern Pacific affects ozone concentrations over the entire tropical Pacific. In the western Pacific including Indonesia, reduced ocean temperatures and convection during El Nino elevates TCO above average levels. The increases in ocean temperature and convection in the eastern Pacific during El Nino reduces levels of TCO in this region from enhanced convective transport of low boundary layer/lower tropospheric ozone into the mid-to-upper troposphere. During La Nina events, opposite conditions prevail which increase (decrease) TCO in the eastern (western) Pacific. These ENSO events produce a planetary scale eastwest "dipole" in TCO between the western and eastern Pacific which has nearly opposite signature between El Nino and La Nina episodes. This dipole feature in TCO is a unique signature of ENSO (e.g., Ziemke and Chandra, 2003). Although ENSO events generate large east-west dipole changes in TCO in the tropical Pacific, stratospheric column ozone (SCO) remains largely unaffected (e.g., Ziemke et al., 1998).

The purpose of this study is to develop a long-record ENSO index based upon column ozone measurements from a number of satellites from 1979 to the present time. An important related result from the derivation of this index is quantifying the zonal invariant property of SCO in the tropics using recent ozone measurements from Aura Microwave Limb Sounder (MLS) and ozone generated from the Goddard Earth Observing System (GEOS) Chemistry-Climate Model (CCM) (Pawson et al., 2008, and references therein). The zonal invariant nature of SCO enables us to develop an ENSO index based upon column ozone measurements that is well calibrated over a long record beginning from 1979. A well calibrated ozone ENSO index is important not just for longterm monitoring of ozone and its photochemical and radiative effects in the troposphere, but also as a diagnostic tool in aiding the development of models of the troposphere including free running global circulation models (GCMs). These models should be capable of reproducing the ozone ENSO index and its relationship with other ENSO index parameters such as sea surface temperature and surface pressure. In the following, Sect. 2 discusses measurements, Sect. 3 discusses zonal variability in stratospheric ozone and the derivation of TCO, Sect. 4 describes the calculation of the ENSO index based upon column ozone, and finally Sect. 5 provides a summary.

\section{Satellite ozone measurements}

Both gridded and level-2 footprint measurements of ozone used in our analyses come from several different satellite instruments: Nimbus 7 Total Ozone Mapping Spectrometer (TOMS) for January 1979-April 1993, National Oceanic and Atmospheric Administration (NOAA) 9 Solar Backscatter Ultraviolet (SBUV/2) for May 1993-July 1996, Earth Probe TOMS for August 1996-September 2004, and the Aura Ozone Monitoring Instrument (OMI) and Microwave Limb Sounder (MLS) for October 2004-July 2009. Also, TOMS, OMI, and SBUV/2 measurements from the "merged" total column ozone record at $5^{\circ}$ latitude $\times 10^{\circ}$ longitude resolution were incorporated (from the TOMS website http: //toms.gsfc.nasa.gov). The MLS ozone profile data were obtained from the NASA Goddard Earth Sciences Data and Information Services Center (DISC). Both TOMS and OMI data include level- 2 footprint and $1^{\circ}$ latitude $\times 1.25^{\circ}$ longitude measurements of column ozone and reflectivity. Level2 data from TOMS and OMI are used to derive stratospheric and tropospheric column ozone from the Convective Cloud Differential (CCD) method (described in section 3). We mention that the level-2 data from nadir viewing TOMS and OMI instruments represent along-track footprint measurements as a function of side scan position and swath position along orbital track. The calculation of stratospheric column 
ozone (SCO) from MLS daily ozone profiles is described by Ziemke et al. (2006). All TOMS and SBUV data are derived from $v 8$ retrievals. (The TOMS Algorithm Theoretical Basis Document (ATBD) for v8 is available from the TOMS webpage.) Version 8 includes many modifications from version 7 including improved a priori tropospheric ozone, an aerosol and sea glint correction, an improved tropospheric efficiency correction, and an offset correction for Earth Probe TOMS measurements. Both gridded and level-2 OMI column ozone and reflectivity were derived using a v8.5 algorithm which is an extension of the $\mathrm{v} 8$ algorithm and includes further improvements including UV cloud pressures of Vasilkov et al. (2008, and references therein) from the OMI UV measurements.

\section{Zonal variability of tropical stratospheric ozone and the CCD method}

A remarkable property of SCO in the low-latitude tropics is that the east-west zonal variability is exceedingly small at only a few DU on all time scales including daily measurements. In this section we will quantify this property using recent Aura MLS ozone measurements and stratospheric ozone generated from a chemistry-climate model. This zonally invariant nature of SCO was recognized by Ziemke et al. (1998) as a means for deriving gridded TCO in the tropics (i.e., the CCD method) which we now discuss briefly.

The CCD method was introduced by Ziemke et al. (1998) using TOMS reflectivity and column ozone level-2 footprint measurements for deriving a long record (1979-1997) dataset of gridded TCO in the tropics. The assumptions of the method are that (1) deep convective clouds in the tropical Pacific have physical cloud tops which often lie at or near the tropopause, and that (2) zonal variability of SCO in these latitudes is small to within a few DU.

The TOMS algorithm determines total column ozone by adding together above-cloud column (the actual measurement) and below-cloud ghost column (based upon climatology). Under assumption (1), by selecting only the smallest of above-cloud column ozone from TOMS in an ensemble of measurements over a specified region, these measurements yield a direct estimation of SCO in the Pacific. Once SCO is determined for the Pacific, property (2) is invoked in that SCO is then assumed to be the same at all longitudes for given fixed latitude. Gridded TCO follows then for each longitude and latitude by subtracting these zonally invariant SCO measurements from gridded near clear sky (scene reflectivity $<0.2$ ) total column ozone from TOMS.

While (1) is true for many deep convective clouds in that some of the physical cloud tops lie at or near the tropopause, the assumption was made that solar UV radiation measured by the TOMS backscatter instrument does not penetrate deeply into the tops of these thick clouds. Later papers by Valks et al. (2003) using GOME data and Vasilkov et al. (2008) using OMI data showed that both visible/nearvisible and UV radiation penetrates deeply into these clouds by many $\mathrm{km}$ (i.e., perhaps by several hundred $\mathrm{hPa}$ ). Thus, if there are significant concentrations of ozone in these clouds, the selection of the minimum above-cloud column amount in the Pacific is no longer an estimate of SCO, but instead an estimate of SCO plus the amount of column ozone lying between the tropopause down to an effective pressure lying within cloud. Incorporating the OMI UV cloud-pressure measurements of Vasilkov et al. (2008) and Ziemke et al. (2009) found that the concentration of ozone in deep convective clouds over much of the tropical western and eastern Pacific Ocean is exceedingly small to within a few ppbv. It was surmised that these low concentrations result largely from low amounts of boundary layer/low tropospheric ozone injected upward into the clouds from deep convection. The original assumption of Ziemke et al. (1998) was not correct regarding solar UV penetration into thick clouds, but the very low ozone measured in these clouds suggests that the CCD method remains a reliable measurement of $\mathrm{SCO}$ in the $\mathrm{Pa}-$ cific.

Assumption (2) regarding the zonal invariant property of SCO in the tropics was assessed by Ziemke et al. (1998) using combined Upper Atmosphere Research Satellite (UARS) Microwave Limb Sounder (MLS), UARS Halogen Occultation Experiment (HALOE), and Stratospheric Aerosol and Gas Experiment (SAGE) limb sounding retrievals. These measurements were limited both spatially and temporally for evaluating this property. The UARS MLS stratospheric ozone measurements extended down to $68 \mathrm{hPa}$ (not a retrieved level, but instead extrapolated and lying several km above the tropopause) and the HALOE and SAGE ozone retrievals, although highly accurate in determining SCO, were limited both temporally and spatially with $\sim 30$ global profile measurements per day for each instrument. It was concluded from these data that zonal variability of SCO in the tropics on monthly time scales is about $5 \mathrm{DU}$ or less (i.e., $\sim 2 \%$ of background ozone or less).

All ozone measurements were derived for monthly means at $5^{\circ} \times 5^{\circ}$ gridding. The version $8 \mathrm{CCD}$ measurements of TCO have an estimated RMS precision error of $3 \mathrm{DU}$ in $5^{\circ} \times 5^{\circ}$ monthly averages. For some of our analysis of CCD measurements a 3-month running average was applied which reduces this RMS uncertainty to 1.7 DU. The RMS precision error of gridded SCO in the tropics measured by the MLS instrument is estimated to be about $6 \mathrm{DU}$ which further reduces to about $1 \mathrm{DU}$ for monthly means. The measurement path length for limb-viewing MLS is about $300 \mathrm{~km}$ (about $3^{\circ}$ of latitude) in the tropical lower stratosphere which is not considered to be of impact in resolving SCO features derived for monthly means. When either TCO or SCO are further averaged over broad regions these RMS errors reduce further such as for $30^{\circ} \times 70^{\circ}$ regions in the Pacific (defined later in this study); for these broad regions the RMS errors in the gridded data are reduced further by a factor of about 9 . 


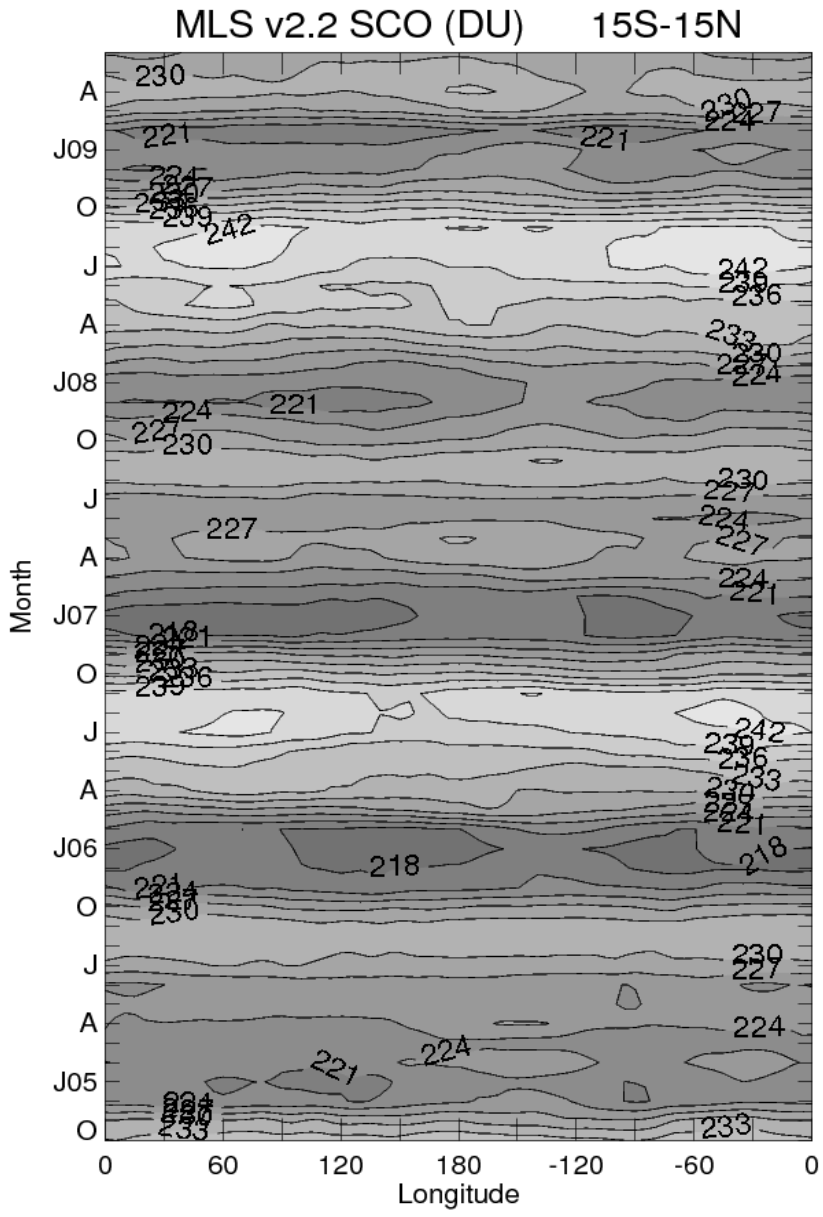

Fig. 1. Time versus longitude Hovmoller diagram of Aura MLS SCO. The data are monthly means and area-averaged between latitudes $15^{\circ} \mathrm{S}$ and $15^{\circ} \mathrm{N}$. The time period is October 2004-May 2009. Contour intervals are $3 \mathrm{DU}$.

\subsection{Zonal variability of tropical SCO from Aura MLS measurements}

The Aura MLS ozone retrievals provide greatly improved space-time coverage and testing of property (2) of the CCD method compared to previous satellite measurements. Figure 1 is a time versus longitude Hovmoller diagram of Aura MLS monthly mean SCO averaged between latitudes $15^{\circ} \mathrm{S}$ and $15^{\circ} \mathrm{N}$. It is noted that the basic conclusions obtained from this $15^{\circ} \mathrm{S}-15^{\circ} \mathrm{N}$ averaging are the same as obtained from averaging over smaller latitude bands in this range. In Fig. 1 the observed temporal variability of SCO is comprised of a coupling of an annual oscillation and Quasi-Biennial Oscillation (QBO) in SCO (Ziemke et al., 2005). This annual oscillation and QBO coupling produced year-to-year changes of $\sim 20 \mathrm{DU}$ with largest SCO of up to $240 \mathrm{DU}$ around the months of August-September in years 2006 and 2008 in Fig. 1. Although temporal changes in SCO may be substantial, the zonal variability appears to be an order of magni-

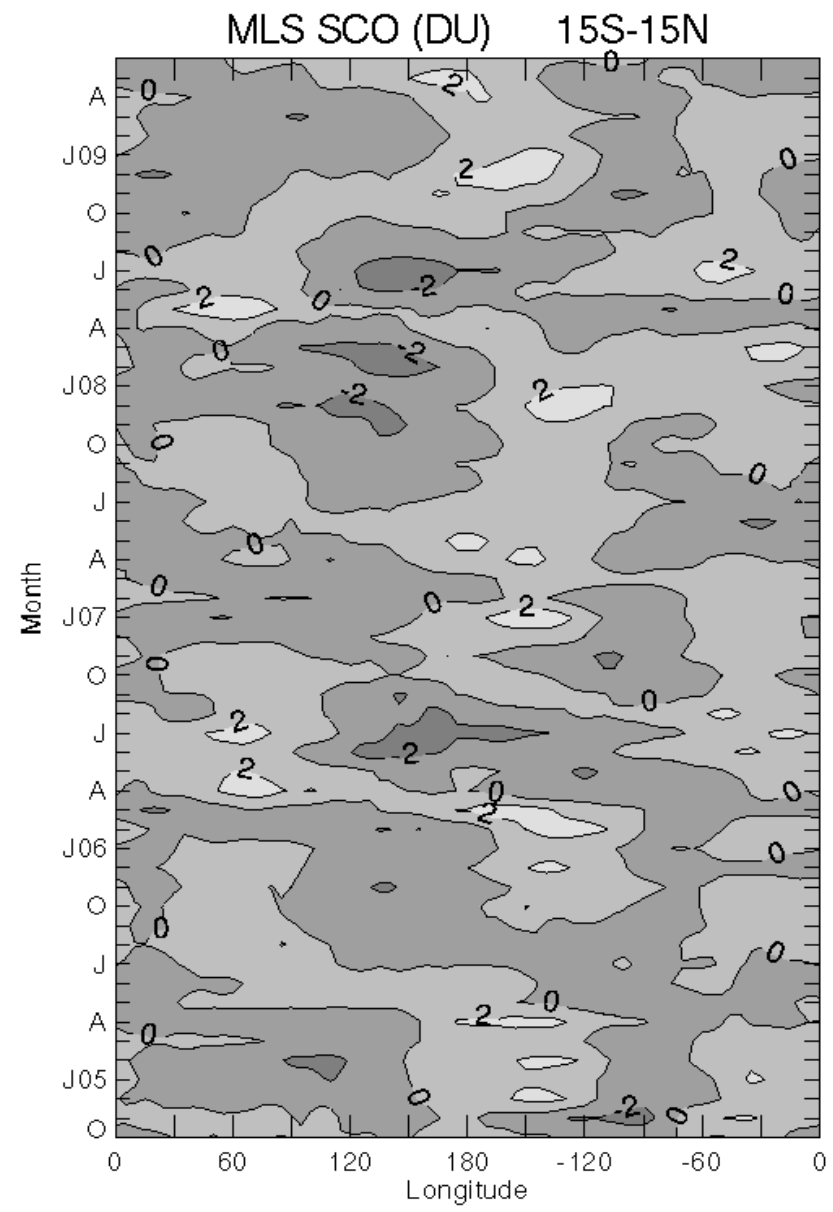

Fig. 2. Same as Fig. 1 but with zonal means removed each month from the measurements.

tude smaller at only a few DU each month. This is illustrated more directly in Fig. 2 which is the same as Figure 1 except that zonal means were removed from SCO each month. In Fig. 2 what remains in the data is a weak coupling of the annual oscillation and QBO with amplitudes $\sim 2 \mathrm{DU}$ which is most evident about the dateline. The MLS data suggest that there may exist a small QBO component in the stratosphere following subtraction of zonal means, but it is weak (at most $\sim 1-2 \mathrm{DU}$ ). It is noted over the five-year record that there is no apparent zonal change associated with the two El Nino events (July 2004-January 2005 and September 2006-January 2007) or the strong La Nina event from August 2008-May 2009. (These dates were determined from the Nino 3.4 sea-surface temperature anomaly ENSO index.)

Figure 3 shows the data further deseasonalized to remove the annual cycle signals present. Deseasonalization of the data was accomplished by first deriving a five-year pseudoclimatology of SCO and subtracting these monthly values from respective monthly time series measurements. What remains in Fig. 3 following removal of annual cycles are small changes in $\mathrm{SCO}$ of about $1 \mathrm{DU}$ on average. Aside from noise 


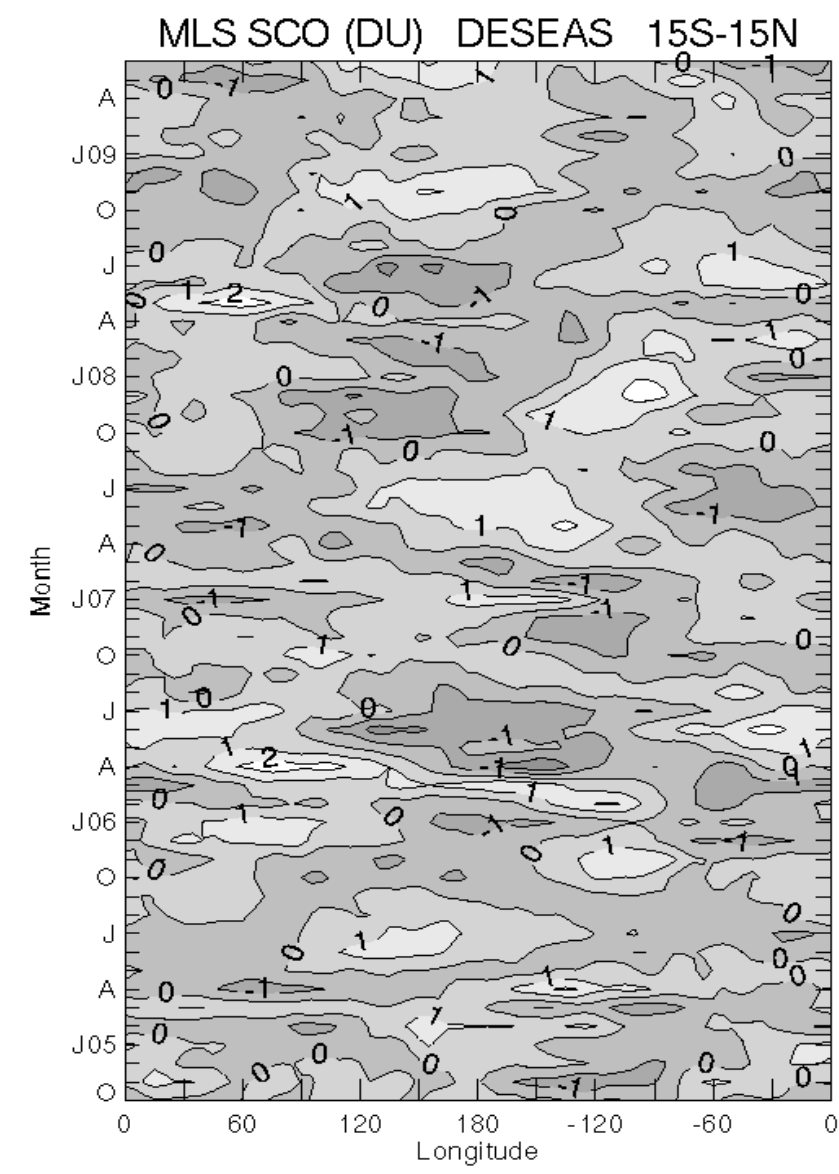

Fig. 3. Same as Fig. 2 but further deseasonalized. Deseasonalization of the data was accomplished by first deriving a five-year pseudo-climatology of SCO and subtracting these monthly values from respective monthly time series measurements.

in the data, some of these small changes may be a manifestation of short time-scale tropical wave disturbances in the stratosphere such as Kelvin waves, equatorial Rossby waves, and mixed Rossby-gravity waves (e.g., Ziemke and Stanford, 1994). These tropical waves (with zonal wavenumbers $\sim 1$ 8) produce small amplitudes in SCO zonal variability of a few DU with time periods of days to weeks. These waves in SCO are also coupled directly with the QBO winds and may produce zonal variations in SCO with a QBO signature. That is, eastward propagating Kelvin wave signals in SCO are measurable when the winds are westward in the lower stratosphere, whereas westward propagating mixed Rossbygravity waves and equatorial Rossby waves in SCO are measurable when these winds are eastward.

Although zonal variability of tropical SCO is small at only a few DU in monthly averages, zonal variability of SCO is small at only a few DU even in daily measurements. Figure 4 shows calculated zonal RMS of daily MLS SCO averaged between $15^{\circ} \mathrm{S}$ and $15^{\circ} \mathrm{N}$. RMS amplitudes on average are $\sim 2$ DU with small variations from intra-seasonal to inter-

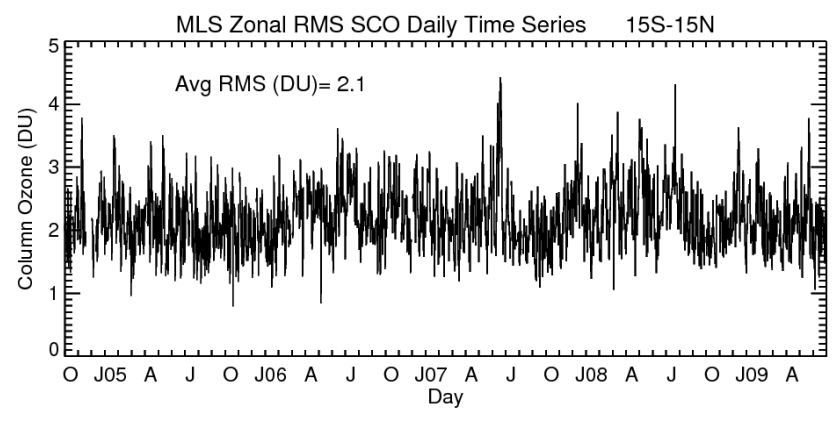

Fig. 4. Calculated zonal RMS of daily MLS SCO (in DU) averaged in the latitude band $15^{\circ} \mathrm{S}$ to $15^{\circ} \mathrm{N}$. RMS amplitudes on average are $\sim 2$ DU with largest values $\sim 3-4$ DU.

annual time scales. Figure 4 suggests that the CCD method in the presence of sufficient number of deep convective clouds in the Pacific can be used to generate SCO (and subsequently $\mathrm{TCO}$ ) on short time scales including daily measurements to a mean uncertainty of about \pm 2 DU.

\subsection{Zonal variability of tropical SCO from the GEOS- CCM}

Our study includes global ozone generated from the Goddard Earth Observing System (GEOS) Chemistry-Climate Model (CCM) (e.g., Pawson et al., 2008, and references therein) for evaluating spatial and temporal characteristics of stratospheric ozone in the tropics. The CCM uses the GEOS-5 atmospheric general circulation model (Reinecker et al., 2008) and the ability to be run with an internally generated QBO. The free running CCM simulates stratospheric ozone, however ozone in the troposphere is relaxed to climatology (Logan et al., 1999) with a 5-day relaxation timescale.

As a self-running model of the atmosphere, the CCM does not invoke ancillary input fields such as winds derived from data assimilation. One of the problems encountered with assimilated winds is excessive eddy transport in the subtropical lower stratosphere (e.g., Tan et al., 2004). As noted by Tan et al. (2004) there are several various possible causes for this excessive subtropical transport including generation of upward propagating features, equatorward propagating features, and meridionally confined features in the process of data assimilation. Excessive eddy transport in models that incorporate assimilated winds can lead to substantial errors in long lived trace gases such as ozone in the tropical and subtropical lower stratosphere.

The CCM does not have this problem with eddy transport and well reproduces the observed zonal invariant behavior of SCO in the tropics. Figure 5 shows Hovmoller diagrams of monthly mean tropical SCO from the CCM averaged over the latitude band $15^{\circ} \mathrm{S}-15^{\circ} \mathrm{N}$. It is noted that the spatial and temporal characteristics of SCO for the six years (1979-1984) plotted in Fig. 5 are typical for the entire 1979-2008 record 


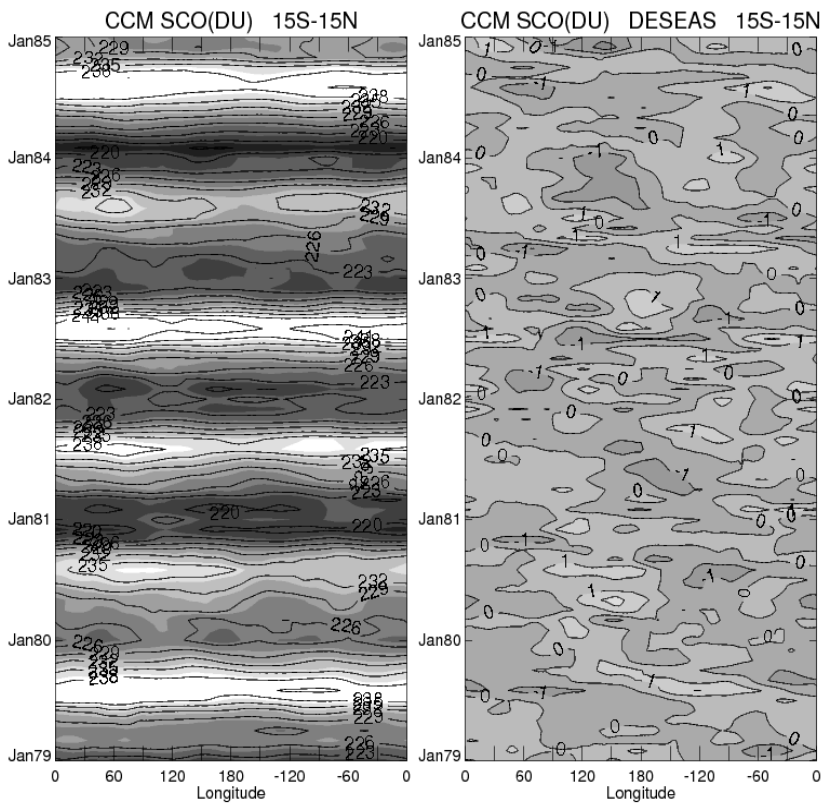

Fig. 5. Hovmoller diagrams of tropical SCO (in DU) from the CCM averaged over the latitude band $15^{\circ} \mathrm{S}-15^{\circ} \mathrm{N}$. (left panel) Original generated SCO. (right panel) Same as left panel except that SCO was further filtered by removing zonal means each month followed by deseasonalization. Figure 5 can be compared with MLS SCO shown in Figs. 1 and 3. The calculated mean zonal RMS for the right panel is $0.7 \mathrm{DU}$ (same as for MLS SCO in Fig. 3).

generated by the CCM. (We mention that since the CCM is a free running model that the ozone plotted in Fig. 5 cannot be compared directly with measurements such as from SAGE over the same time record.) The left panel in Fig. 5 is the original modeled SCO and the right panel is the same except that SCO was further filtered by removing zonal means each month followed by deseasonalization. The left and right panels in Fig. 5 can be compared with MLS SCO plotted in Figs. 1 and 3, respectively. In the left panel, temporal variability is dominated by an annual oscillation signal coupled with QBO (i.e., similar to Fig. 1 for MLS). The right panel in Fig. 5 shows that following removal of zonal means and deseasonalization that what remains are small zonal anomalies $\sim 1$ DU, much like Fig. 3 for MLS. The calculated zonal RMS for SCO in Fig. 5 (right panel) is 0.7 DU averaged over the six-year record. There are several contributing factors causing the zonal variability in SCO to be so small. The first is that the meridional wind is very small in the tropics compared to the zonal wind. The second factor is that the meridional gradient in ozone is also very small. A third possible factor is that there are very small zonal variations in the production and destruction of ozone in the tropics. The combination of these factors act in concert to cause zonal variation to be exceedingly small in tropical stratospheric ozone.

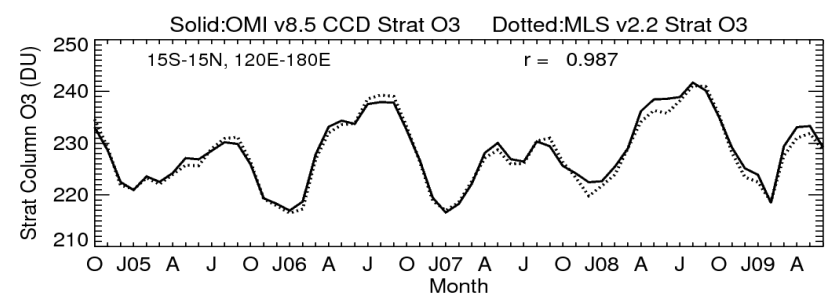

CCD Strat O3 Minus MLS Strat O3

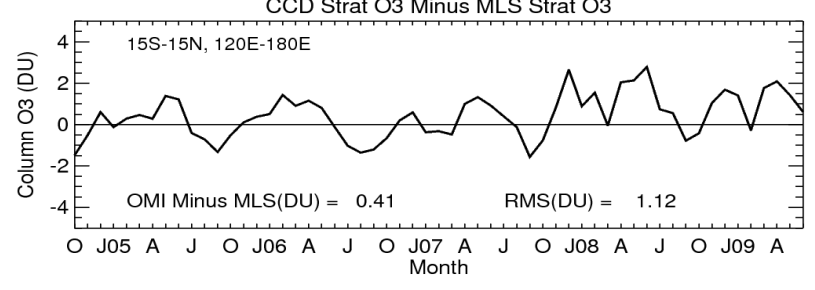

Fig. 6. (top) Monthly mean MLS SCO and CCD SCO from OMI for the western Pacific region $\left(15^{\circ} \mathrm{S}-15^{\circ} \mathrm{N}, 120^{\circ} \mathrm{E}-180^{\circ} \mathrm{E}\right)$. (bottom) Difference between the two time series (CCD minus MLS SCO).

Our analyses of the vertical ozone profiles from the CCM and MLS measurements (figures not shown) indicate that vertical column gradients in ozone (in DU per km altitude) of these small remaining zonal variabilities in SCO in Figures 3 and 5 are concentrated between the tropopause and $\sim 25-30 \mathrm{~km}$ altitude with substantial month-by-month pattern changes. The largest vertical column gradients are found to exceed $0.5 \mathrm{DU}$ per $\mathrm{km}$ in some months. The nature of these anomalies suggests the presence of episodic planetary-scale waves such as Kelvin waves and mixed Rossby-gravity waves in both the measured and simulated stratospheric ozone fields. Studies have suggested that the momentum/energy absorption of Kelvin waves provides substantial forcing of the eastward phase of the QBO winds and temperatures (e.g. Ern and Preusse, 2009, and references therein). It is beyond the scope and main theme of our study to evaluate the properties of these tropical waves in the context of the QBO. The important result is that zonal variability in tropical SCO is exceeding small in the CCM, just as it is for MLS SCO.

\section{Development of the ozone ENSO index (OEI)}

We will demonstrate in this section that one can derive a high precision ENSO index in tropospheric ozone directly from total column ozone using the zonal invariant property of tropical SCO. Figure 6 compares monthly mean MLS and CCD SCO in the western Pacific $\left(15^{\circ} \mathrm{S}-15^{\circ} \mathrm{N}, 120^{\circ} \mathrm{E}-180^{\circ} \mathrm{E}\right)$ for October 2004-mid-2009. The top frame in Fig. 6 plots these two time series together while the bottom frame shows their differences. The MLS and OMI CCD measurements in Fig. 6 agree to within $\sim 1$ DU in either mean offset or RMS of their difference. Averaging SCO over a similar region in the eastern Pacific or averaging together both eastern and 


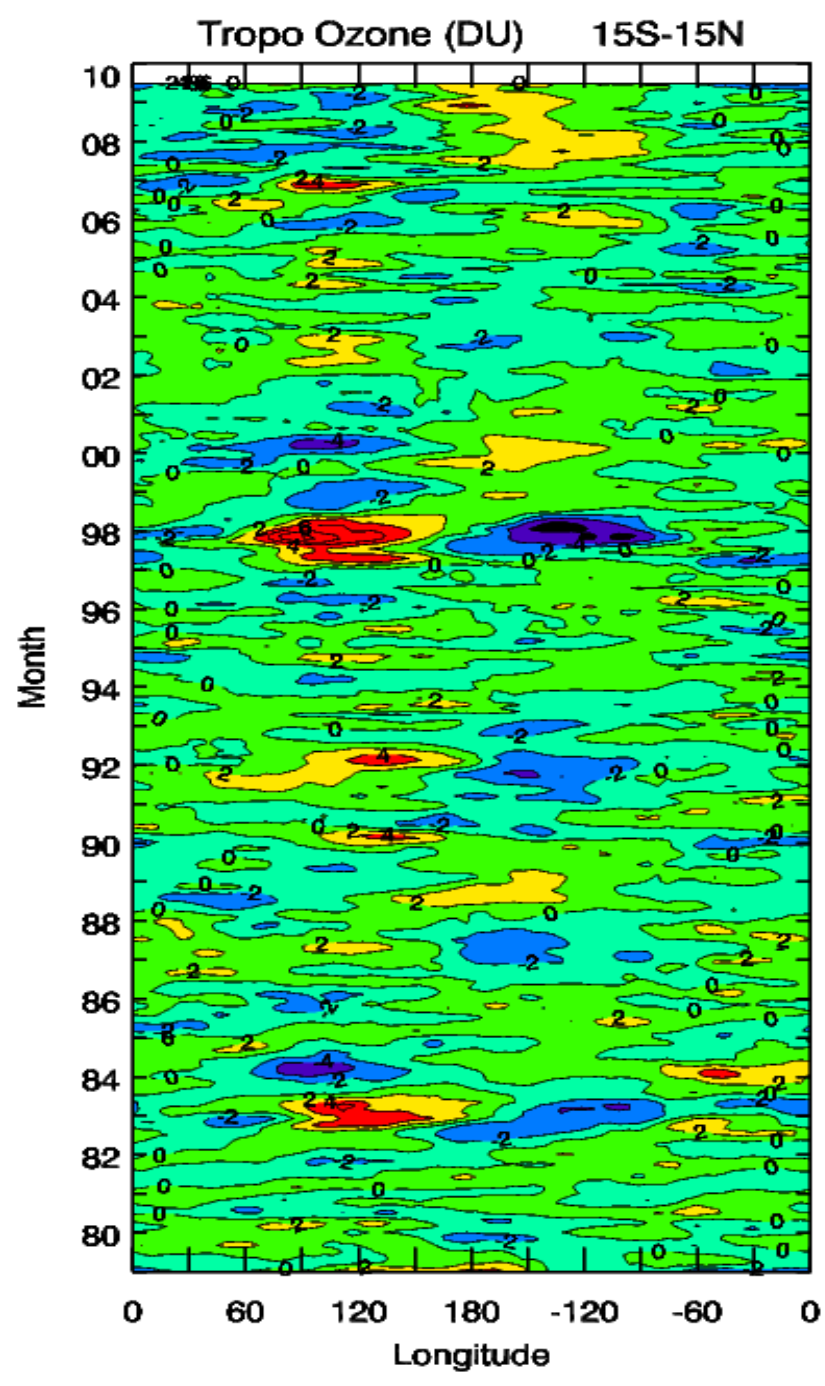

Fig. 7. Time versus longitude Hovmoller diagram of monthly mean TCO (in DU) from TOMS/OMI measurements averaged between latitudes $15^{\circ} \mathrm{S}$ and $15^{\circ} \mathrm{N}$ for the period 1979-2009 (see text). The data were filtered to remove the zonal mean each month and further deseasonalized as in Fig. 3. A 3-month running average was applied. The numbers listed on the vertical axis refer to January of the particular year.

western Pacific yields nearly identical results Unlike Ziemke et al. (2006) (using previous versions of OMI and MLS), no offset adjustment was made to the MLS SCO measurements in comparing with CCD SCO. The excellent agreement between the two measurements in Fig. 6 suggests that the CCD methodology works well and that it is possible to combine TOMS and OMI CCD measurements in deriving a long record of TCO.

Figure 7 shows a time versus longitude Hovmoller diagram of monthly mean TCO averaged between latitudes $15^{\circ} \mathrm{S}$ and $15^{\circ} \mathrm{N}$ for the period 1979-2009. The data were filtered to remove the zonal mean each month and were fur- ther deseasonalized as in Fig. 3. For this long record, a 3 -month running average was applied. The TCO data in Fig. 7 are comprised of CCD measurements from Nimbus 7 TOMS (January 1979-April 1993), Earth Probe TOMS (August 1996-September 2004), and OMI (October 2004-July 2009). In addition, the temporal gap of missing CCD measurements for May 1993-July 1996 was filled in using total column ozone from SBUV/2 under the property that zonal variation in total column ozone in the low-latitude tropics is mostly all tropospheric in origin. (That is, after removing zonal means from total column ozone and deseasonalizing the data, the remaining zonal variability is essentially all tropospheric as indicated by Fig. 3.) Our analysis of SBUV data shows that total column ozone from SBUV is more accurate and precise than TOMS total column ozone. However, despite good measurements of total column ozone from SBUV there is little actual ozone profile information from SBUV below the ozone number density peak $(\sim 20-30 \mathrm{hPa}$ in the tropics). Despite problems with the SBUV ozone profiles, the total column ozone is highly precise and at least as good as TOMS for use in Fig. 7 under the premise of zero zonal variation of SCO.

The TCO plotted in Fig. 7 represent nearly cloud-free measurements (i.e., footprint scene reflectivity $<0.2$ ) for TOMS and OMI, and essentially cloud-free as well for SBUV/2 due to small cloud fractions from large nadir footprint size ( $\sim 200 \mathrm{~km}$ diameter). Because of property (2) of the CCD method, the data plotted in Fig. 7 are equivalent to total column ozone filtered for low-reflectivity scenes with zonal means removed each month and deseasonalized.

The long record of TCO in Fig. 7 depicts many El Nino and La Nina events. Significant El Nino-induced positive ozone changes ( $>4 \mathrm{DU}$, colored red) occurred in the western Pacific in 1982-1983, 1990-1992, 1997-1998, and 2006. La Nina induced changes greater than +2 DU (colored yellow) in the eastern Pacific occurred in 1988-1989, 1999-2000, and 2007-2009. These ENSO events all occurred in northern hemisphere late autumn-winter months with the most intense being the El Nino episode in 1997-1998. For either El Nino or La Nina, a positive anomaly in TCO in the tropical Pacific coincides with a negative anomaly opposite the dateline. This Pacific dipole feature in tropospheric ozone for ENSO events will be used to derive an ENSO index based upon tropospheric ozone. Our study defines this index under simplest terminology as the "Ozone ENSO Index" (OEI).

The OEI in TCO is derived using calculations of temporal cross-correlation with Nino 3.4 and SOI ENSO indices. The TCO data for this statistical analysis (using measurements from Fig. 7) were extended out to low subtropical latitudes in effort to better evaluate latitudinal structure of the ENSO signatures. (Pseudo climatologies from SAGE II and Aura MLS SCO were incorporated to select only those months at given latitude where zonal RMS variability of SCO on average is less than 3 DU.) The OEI was obtained by first averaging gridded TCO each month over two broad equal-area 

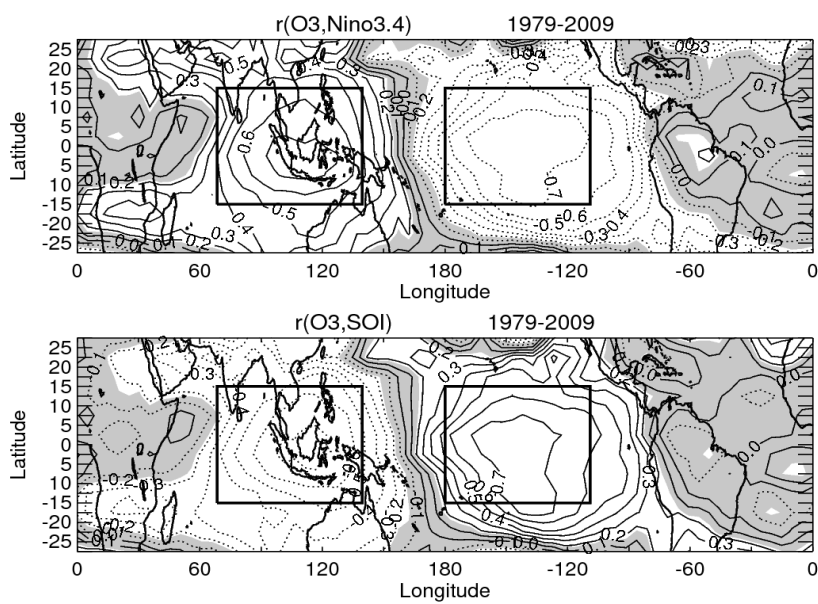

Fig. 8. Maps of temporal correlation between gridded CCD TCO and Nino 3.4 (top frame) and SOI (bottom frame) time series. An optimal OEI was determined by area-averaging TCO over two broad regions of large correlations west and east of the dateline as indicated by the rectangles (latitude ranges $15^{\circ} \mathrm{S}-15^{\circ} \mathrm{N}$, and longitude ranges $70^{\circ} \mathrm{E}-140^{\circ} \mathrm{E}$ and $110^{\circ} \mathrm{W}-180^{\circ}$, respectively). Grey shaded areas are not statistically significant at $99.9 \%$ confidence level (i.e., $0.1 \%$ significance level) between time series (e.g., Hogg and Craig, 1978).

regions of large correlations west and east of the dateline which are indicated by the dark rectangles in Fig. 8 (latitude ranges $15^{\circ} \mathrm{S}-15^{\circ} \mathrm{N}$, and longitude ranges $70^{\circ} \mathrm{E}-140^{\circ} \mathrm{E}$ and $110^{\circ} \mathrm{W}-180^{\circ} \mathrm{W}$, respectively). The OEI time series was then derived by subtracting TCO in the eastern Pacific region from TCO in the western Pacific region each month. This differencing of western minus eastern Pacific TCO removes potential instrument calibration errors including bias and/or long-term drift for a particular instrument. The OEI as a result is well calibrated over the long record regardless of which ozone instrument is used in a given month or series of consecutive months.

Figure 9 shows the resulting OEI time series (in bold) plotted versus Nino 3.4 (thin curve, top frame) and SOI (thin curve, bottom frame). For scaling purposes in Fig. 9, the Nino 3.4 index (SOI index) was multiplied by +3 $(-2)$. These scaling numbers are close to the derived sensitivity constants of TCO time series with reference Nino 3.4 or SOI ENSO indices from regression analysis. That is, for the Nino 3.4 index the constant $\beta$ from $\mathrm{TCO}=\beta \cdot$ Nino $3.4+\varepsilon$ is $2.93 \pm 0.21(2 \sigma)$ DU-K ${ }^{-1}$. Similarly, $\beta=-1.72 \pm 0.13(2 \sigma) \mathrm{DU}_{-\mathrm{hPa}}{ }^{-1}$ for the SOI index.

As was noted above for Fig. 9, zonal variation of tropospheric ozone can be determined directly from total column ozone measurements under the property of small zonal variability in tropical SCO. Figure 10 shows the OEI derived using total column ozone from the merged ozone dataset. Correlations with both Nino 3.4 and SOI are reduced slightly from those in Fig. 9. The smaller correlations in Fig. 10
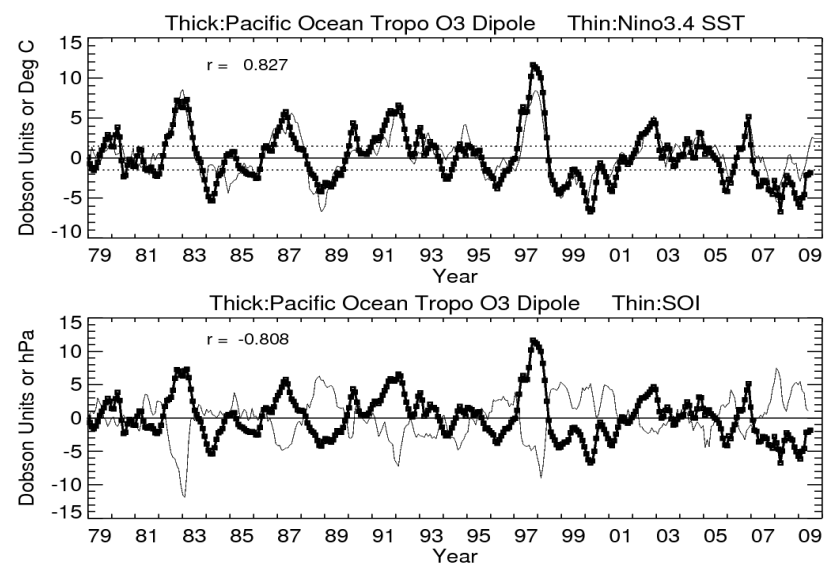

Fig. 9. OEI time series (in bold) plotted versus Nino 3.4 (thin curve, top frame) and SOI (thin curve, bottom frame). The Nino 3.4 index (SOI index) was multiplied by $+3(-2)$ for scaling with the OEI time series. These scaling numbers are close to derived sensitivity constants of TCO time series in reference to Nino 3.4 or SOI from regression analysis. For Nino 3.4 the constant $\beta$ from TCO $=\beta$ Nino $3.4+\varepsilon$ is $2.93 \pm 0.21(2 \sigma)$ DU-K ${ }^{-1}$. Similarly, $\beta=-1.72 \pm 0.13(2 \sigma) \mathrm{DU}_{-\mathrm{hPa}}{ }^{-1}$ for the SOI index.
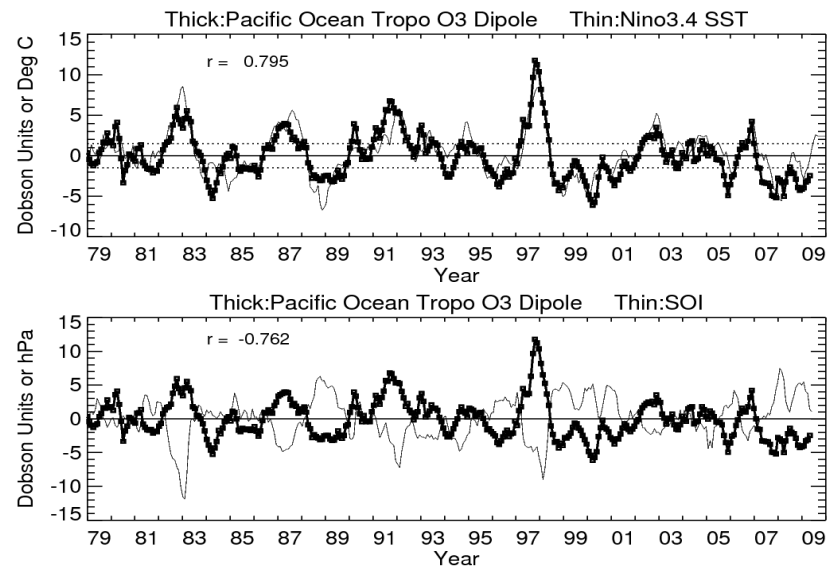

Fig. 10. Same as Fig. 9, but with OEI derived using total column ozone from the merged ozone dataset. The sensitivity coefficients for Nino 3.4 and SOI are $\beta=2.44 \pm 0.20(2 \sigma)$ DU-K ${ }^{-1}$, and $-1.42 \pm$ $0.13(2 \sigma) \mathrm{DU}_{-\mathrm{hPa}^{-1}}$, respectively.

may be caused in part by an absence of cloud filtering of the data as was done for the TOMS and OMI CCD measurements in Fig. 7. The sensitivity coefficients in Fig. 10 for Nino 3.4 and SOI are $\beta=2.44 \pm 0.20(2 \sigma)$ DU-K ${ }^{-1}$, and $-1.42 \pm 0.13(2 \sigma) \mathrm{DU}_{-} \mathrm{hPa}^{-1}$, respectively. These numbers are smaller than for the clear-sky measurements in Fig. 9 which is consistent with smaller tropospheric ozone concentrations associated with deep convective clouds in the Pacific.

The Aura MLS SCO measurements from Fig. 3 are used to estimate precision errors in derived OEI from total column ozone from the assumption of zero zonal variability in 


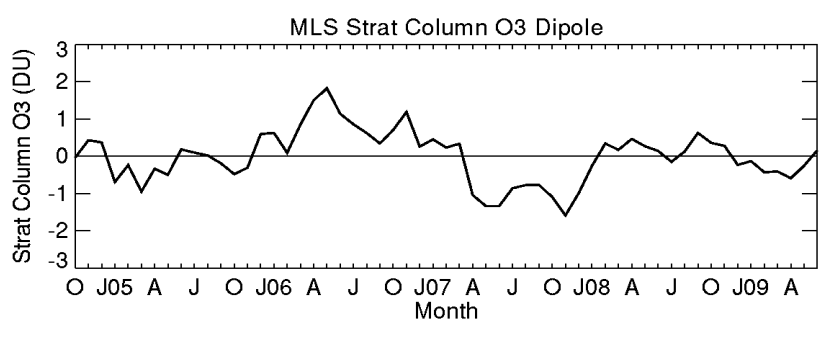

Fig. 11. Time series of Aura MLS deseasonalized SCO from Fig. 3 derived by averaging data over the two OEI western and eastern Pacific regions $\left(15^{\circ} \mathrm{S}-15^{\circ} \mathrm{N}, 70^{\circ} \mathrm{E}-140^{\circ} \mathrm{E}\right.$ and $15^{\circ} \mathrm{S}-15^{\circ} \mathrm{N}$, $110^{\circ} \mathrm{W}-180^{\circ}$, respectively), differencing them each month (western minus eastern Pacific) with a three-month running average applied. This time series provides an estimation of the precision errors (in DU) in the calculated tropospheric OEI from total column ozone.

SCO. Just as for the derivation of the OEI, the deseasonalized SCO data from Fig. 3 are averaged over the two western and eastern Pacific sectors (again, these regions are $15^{\circ} \mathrm{S}$ $15^{\circ} \mathrm{N}, 70^{\circ} \mathrm{E}-140^{\circ} \mathrm{E}$ and $15^{\circ} \mathrm{S}-15^{\circ} \mathrm{N}, 110^{\circ} \mathrm{W}-180^{\circ}$, respectively), differenced (western minus eastern Pacific) with a three-month running average applied. The derived time series is shown in Fig. 11. On average, zonal variability in SCO is near zero with up to $\sim 1-2 \mathrm{DU}$ in the most extreme. The calculated temporal RMS value in Fig. 11 is 0.7 DU.

\section{Summary}

We have developed an ozone ENSO index (OEI) based upon ozone measurements in the tropical Pacific region. This index is derived from total column ozone measured from Nimbus 7 TOMS, Earth Probe TOMS, NOAA SBUV, and Aura OMI satellite instruments covering a time period from 1979 to the present. The OEI is derived by first averaging monthly column ozone over two broad regions of the western and eastern Pacific $\left(15^{\circ} \mathrm{S}-15^{\circ} \mathrm{N}, 70^{\circ} \mathrm{E}-140^{\circ} \mathrm{E}\right.$, and $15^{\circ} \mathrm{S}-$ $15^{\circ} \mathrm{N}, 110^{\circ} \mathrm{W}-180^{\circ} \mathrm{W}$, respectively) and then taking their difference (western minus eastern Pacific TCO). The resulting time series is then deseasonalized and a 3-month running average is applied. This differencing is important since it yields a self-calibrating ENSO index for the long record which is independent of offsets or calibration drifts for a particular instrument.

Central to deriving the OEI in the tropics is the assumption of near zonal invariance of stratospheric column ozone (SCO). Our study has demonstrated this property from Aura MLS measurements and the Goddard Earth Observing System (GEOS) Chemistry-Climate Model (CCM). Previous studies have indicated that the zonal variability of SCO in the tropics is small in monthly averages at about $5 \mathrm{DU}$ or less. This conclusion was based upon SAGE and UARS HALOE (both with sparse temporal and spatial coverage), and UARS MLS which extended only down to $68 \mathrm{hPa}$ (sev- eral $\mathrm{km}$ above the tropopause). The recent Aura MLS ozone measurements provide a better evaluation of the zonal variability of SCO. Analysis of the Aura MLS data indicates that the zonal variability of monthly mean SCO in the tropics is small at $\sim 1-2$ DU. Aside from noise in the measurements, this may be a manifestation of unresolved tropical waves in SCO such as short timescale ( $\sim$ days to weeks) Kelvin waves, mixed Rossby gravity waves, equatorial Rossby waves, etc. (beyond the scope of this study). These waves in SCO are coupled directly with the phase of the QBO winds and may produce small zonal variations in $\mathrm{SCO}$ with a $\mathrm{QBO}$ signature.

When deseasonalized monthly measurements of MLS SCO are averaged over the western and eastern Pacific regions as is done for deriving the OEI, the zonal variations are near zero on average and $\sim 1-2 \mathrm{DU}$ at extreme $(0.7 \mathrm{DU}$ RMS). Daily measurements show further that zonal variability of SCO is also small at $\sim 2$ DU RMS on average. This suggests that the assumption of zonal invariance in SCO applies to time averages much shorter than monthly means including daily measurements given a sufficient number of deep convective clouds in the Pacific. These numbers provide a quantitative assessment of the accuracy and precision of deriving the OEI from total column ozone measurements. (The "merged" total column ozone measurements are made available to the public from the website http://acdb-ext.gsfc. nasa.gov/Data_services/merged/index.html.)

Although El Nino events coincide with anomalously dry conditions over Indonesia and enhanced ozone in this region from biomass burning (both natural and anthropogenic), the largest changes in tropospheric ozone are dynamically induced by a planetary-scale shift in ocean temperatures and convective transport (Chandra et al., 2002, 2009). Historically, the periodicity of recurring El Nino or La Nina events varies on average from about 2 to 7 years based upon a long record of Tahiti and Darwin surface pressure measurements since the late 1800's. Over the last several years, however, El Nino events have recurred frequently in 2002, 2004, 2006, and 2009. For clear-sky ozone measurements a $+1 \mathrm{~K}$ change in Nino 3.4 index corresponds to $+2.9 \mathrm{DU}$ change in the OEI, while a $+1 \mathrm{hPa}$ change in SOI coincides with a -1.7 DU change in the OEI. For ozone measurements under all cloud conditions these numbers are reduced to $+2.4 \mathrm{DU}$ and $-1.4 \mathrm{DU}$, respectively. These results should be useful in evaluating climate models predicting long term changes in ozone and other trace gases. Models of the troposphere including free running GCMs should be capable of reproducing the OEI and its physical relationship with other ENSO induced changes in other geophysical parameters such as sea surface temperature and surface pressure. The OEI time series for both clear-sky and all-cloud conditions are updated periodically and can be obtained from the Goddard tropospheric ozone website at http://toms.gsfc.nasa.gov. 
Acknowledgements. The authors thank the Aura OMI and MLS instrument and algorithm teams for producing the satellite measurements used in this study. We especially thank Stacey Hollandsworth Frith and Richard Stolarski for development of the extensive "merged" total ozone data set from combined TOMS and SBUV measurements. We also especially thank Nathaniel Livesey and Lucien Froidevaux from the MLS team for their helpful guidance regarding the MLS data. Funding for this research was provided in part by Goddard Earth Science Technology (GEST) grant NGC5-494.

Edited by: M. Dameris

\section{References}

Chandra, S., Ziemke, J. R., Min, W., et al.: Effects of 1997-1998 El Nino on tropospheric ozone and water vapor, Geophys. Res. Lett., 25, 3867-3870, 1998.

Chandra, S., Ziemke, J. R., Bhartia, P. K., et al.: Tropical tropospheric ozone: Implications for dynamics and biomass burning, J. Geophys. Res., 107(D14), 4188, doi:10.1029/2001JD000447, 2002.

Chandra, S., Ziemke, J. R., Duncan, B. N., et al.: Effects of the 2006 El Nino on tropospheric ozone and carbon monoxide: Implications for dynamics and biomass burning, Atmos. Chem. Phys., 9, 4239-4249, 2009,

http://www.atmos-chem-phys.net/9/4239/2009/.

Ern, M. and Preusse, P.: Wave fluxes of equatorial Kelvin waves and QBO zonal wind forcing derived from SABER and ECMWF temperature space-time spectra, Atmos. Chem. Phys., 9, 39353986, 2009,

http://www.atmos-chem-phys.net/9/3935/2009/.

Fujiwara, M., Kita, K., Kawakami, S., et al.: Tropospheric ozone enhancements during the Indonesian forest fire events in 1994 and in 1997 as revealed by ground-based observations, Geophys. Res. Lett., 26, 2417-2420, 1999.

Hogg, R. V. and Craig, A. T.: Introduction to Mathematical Statistics, Macmillan, New York, USA, 4th Edition, 1978.

Langford, A. O., O'Leary, T. J., Masters, C. D., et al.: Modulation of middle and upper tropospheric ozone at Northern latitudes by the El Nino/Southern Oscillation, Geophys. Res. Lett., 25, 26672670, 1998.

Logan, J. A.: An analysis of ozonesonde data for the troposphere: Recommendations for testing 3-D models, and development of a gridded climatology for tropospheric ozone, J. Geophys. Res., 104, 16115-16149, 1999.

Logan, J. A., Megretskaia, I., Nassar, R., et al.: Effects of the 2006 El Nino on tropospheric composition as revealed by data from the Tropospheric Emission Spectrometer (TES), Geophys. Res. Lett., 35, L03816, doi:10.1029/2007GL031698, 2008.

Martin, R. V., Sauvage, B., Folkins, I., et al.: Space-based constraints on the production of nitric oxide by lightning, J. Geophys. Res., 112, D09309, doi:10.1029/2006JD007831, 2007.

Newchurch, M. J., Liu, X., and Kim, J. H.: Lower tropospheric ozone (LTO) derived near TOMS mountainous regions, J. Geophys. Res., 106, 20403-20412, 2001.

Pawson, S., Stolarski, R. S., Douglass, A. R., et al.: Goddard Earth Observing System chemistry-climate model simulations of stratospheric ozone-temperature coupling be- tween 1950 and 2005, J. Geophys. Res., 113, D12103, doi:10.1029/2007JD009511, 2008.

Peters, W., Krol, M., Dentener, F., et al.: Identification of an El Nino-Southern Oscillation signal in a multiyear global simulation of tropospheric ozone, J. Geophys. Res., 106(D10), 1039810402, 2001.

Rienecker, M. M., Suarez, M. J., Todling, R., et al.: The GEOS5 Data Assimilation System - Documentation of versions 5.0.1, 5.1.0, and 5.2.0, Technical Report Series on Global Modeling and Data Assimilation, 27, 2008.

Sauvage, B., Martin, R. V., von Donkelaar, A., et al.: Quantification of the factors controlling tropical tropospheric ozone and the South Atlantic maximum, J. Geophys. Res., 112, D11309, doi:10.1029/2006JD008008, 2007.

Sudo, K. and Takahashi, M.: Simulation of tropospheric ozone changes during 1997-1998 El Nino: Meteorological impact on tropospheric photochemistry, Geophys. Res. Lett., 23, 40914094, 2001.

Tan, W. W., Geller, M. A., Pawson, S., et al.: A case study of excessive subtropical transport in the stratosphere of a data assimilation system, J. Geophys. Res., 109, D11102, doi:10.1029/2003JD004057, 2004.

Thompson, A. M., Witte, J. C., Hudson, R. D., et al.: Tropical tropospheric ozone and biomass burning, Science, 291, 2128-2182, 2001.

Trenberth, K. E.: The definition of El Nino, B. Amer. Meteorol. Soc., 78(12), 2771-2777, 1997.

Valks, P. J. M., Koelemeijer, R. B. A., van Weele, M., et al.: Variability in tropical tropospheric ozone: Analysis with Global Ozone Monitoring Experiment observations and a global model, J. Geophys., Res., 108(D11), 4328, doi:10.1029/2002JD002894, 2003.

Vasilkov, A., Joiner, J., Spurr, R., et al.: Evaluation of the OMI cloud pressures derived from rotational Raman scattering by comparisons with other satellite data and radiative transfer simulations, J. Geophys. Res., 113, D15S19, doi:10.1029/2007JD008689, 2008.

Zeng, G. and Pyle, J. A.: Influence of El Nino Southern Oscillation on stratosphere/troposphere exchange and the global tropospheric ozone budget, Geophys. Res. Lett., 32, L0814, doi:10.1020/2004GL021353, 2005.

Ziemke, J. R. and Stanford, J. L.: Quasi-biennial oscillation and tropical waves in total ozone, J. Geophys. Res., 99, 2304123056, 1994.

Ziemke, J. R., Chandra, S., and Bhartia, P. K.: Two new methods for deriving tropospheric column ozone from TOMS measurements: The assimilated UARS MLS/HALOE and convective-cloud differential techniques, J. Geophys. Res., 103, 22115-22127, 1998.

Ziemke, J. R. and Chandra, S.: La Nina and El Ninoinduced variabilities of ozone in the tropical lower atmosphere during 1970-2001, Geophys. Res. Lett., 30, 1142, doi:10.1029/2002GL016387, 2003.

Ziemke, J. R., Chandra, S., and Bhartia, P. K.: A 25-year data record of atmospheric ozone in the Pacific from Total Ozone Mapping Spectrometer (TOMS) cloud slicing: Implications for ozone trends in the stratosphere and troposphere, J. Geophys. Res. Lett., 110, D15105, doi:10.1029/2004JD005687, 2005.

Ziemke, J. R., Chandra, S., Duncan, B. N., et al.: Tropospheric ozone determined from Aura OMI and MLS: Evaluation of mea- 
surements and comparison with the Global Modeling Initiative's Chemical Transport Model, J. Geophys. Res., 111, D19303, doi:10.1029/2006JD007089, 2006.
Ziemke, J. R., Joiner, J., Chandra, S., et al.: Ozone mixing ratios inside tropical deep convective clouds from OMI satellite measurements, Atmos. Chem. Phys., 9, 573-583, 2009. 